\title{
How We Can Enhance Spectator Attendance for the Sustainable Development of Sport in the Era of Uncertainty: A Re-Examination of Competitive Balance
}

\author{
Sang Hun Sung ${ }^{1}$, Doo-Seung Hong ${ }^{2, *}$ and Soo Young Sul ${ }^{3}$ \\ 1 Center for Asian and Pacific Studies, University of Iowa, Iowa City, IA 52242, USA; \\ sanghun-sung@uiowa.edu \\ 2 Department of Sociology, Seoul National University, Seoul 08826, Korea \\ 3 Department of Sport Management, Kyonggi University, Suwon, Kyonggi-do 16227, Korea; \\ sysul@kyonggi.ac.kr \\ * Correspondence: dshong@snu.ac.kr
}

Received: 31 July 2020; Accepted: 28 August 2020; Published: 31 August 2020

\begin{abstract}
This study seeks to find factors that determine the mobilization of spectators in games of the Korean professional baseball league for sustainable development. In particular, it re-examines the uncertainty-of-outcome hypothesis by looking at the effect of competitive balance (CB) on seat occupancy in stadiums. Data for 2160 games over three years (2015-2017) from the archives of the Korea Baseball Organization (KBO) were analyzed. The results show that the $\mathrm{CB}$ of the home team, with the entire teams, affects seat occupancy rate (SOR). It is also shown that there exists an inverted U-shaped curvilinear relationship between CB and SOR. However, the winning percentage of the home team in the entire league had a significant impact on the SOR. This implies that the overall athletic performance of the home team in the league competing with all other teams is much more important than the home team's competitive balance in the season played before the game, for attracting fans to the stadium.
\end{abstract}

Keywords: competitive balance; spectator attendance; seat occupancy; professional baseball; Korean sports

\section{Introduction}

Professional sports are a cultural phenomenon that has been deeply embedded in the daily life of people [1]. They have played an essential role in integrating the urban community, culturally and socially. Sport events have contributed to feelings of national identity, social cohesion and community empowerment, and promoted sustainable development [2,3]. Sport plays a role of achieving the sustainable development goals [4]. In Korea, professional sports have shown continuous growth due to the improvement of players' performance, the rising popularity of watching sports and support from the government [5]. Gate attendance is a major resource for the annual revenues of professional sports teams, with a few exceptions such as professional cycling teams [6]. Growth of attendance is essential to the subsistence and sustainable development of the teams since it is closely related to income from season tickets, telecasts, sponsorship, sales of licensed items, sales in on-site shops in stadiums, etc. $[7,8]$. It is also critical to the competitiveness of the sports industry as a whole, as well as that of individual teams $[9,10]$.

In the professional sports market, a competitive advantage emerges when teams enhance the quality of games together with competing teams. The quality of commercial goods produced by 
professional sports depends on how teams provide exciting games to fans as their consumers. Therefore, the most attractive asset is the excitement of very competitive matches between two teams. One team being far ahead of the other in professional sports leagues may negatively affect its sound growth. However, competitive imbalance exists in the leagues to a certain extent. An affiliation with an exclusive hometown of an individual team produces a difference in the level of profits due to such factors as home stadium size, population size, team loyalty, team management, the performance of home team players, and the presence of star players in a team's roster. Differences in profits and investment bring about inter-team competitive imbalance [11].

Previous research on professional sports games has mainly focused on the United States (US) [12-14] and European countries [15-18], and to a lesser extent on other regions [19-21]. In recent years, however, the Asian sport industry and athletes has continuously risen and become more visible in global sporting arenas [22]. This paper contributes to the sports literature by exploring whether the theoretical perspectives and findings derived from North American and European professional sports leagues can be applied to other national contexts such as Korean professional teams, which have experienced relatively recent development $[10,23]$. Professional baseball has become the most popular sport in Korea, followed by professional soccer, basketball, and volleyball [24]. The professional baseball league started with six teams in 1982, and later in 2015, expanded to 10 teams nationwide (Appendix A). Since its establishment, it has introduced a region-based system of baseball teams and operated home-and-away games. Each team plays 144 games per year. These teams have a home stadium in eight cities because Seoul possesses three teams.

Professional baseball in Korea faced recession during the period of the late 1990s and the mid-2000s due to an insufficient number of spectators (see Figure 1). Therefore, most teams suffered from financial deficits without subsidies from their host company. Since the late 2000s, however, the number of spectators has increased thanks to such situational factors as the introduction of a five-day workweek, excellent performances in international championships, 'sportainment' (sports plus entertainment) introduced by each club, and an increase in female spectators, among others. Professional baseball spectators recorded 1,430,000 in 1982, the year of the league's inauguration, but reached 8,400,000 in 2017. The cumulative number of spectators up to the year 2017 exceeded 150,000,000 in 18,540 matches. In 2017, the total sales volume of the 10 clubs was 520 billion won (equivalent to 441 million US dollars) [7].

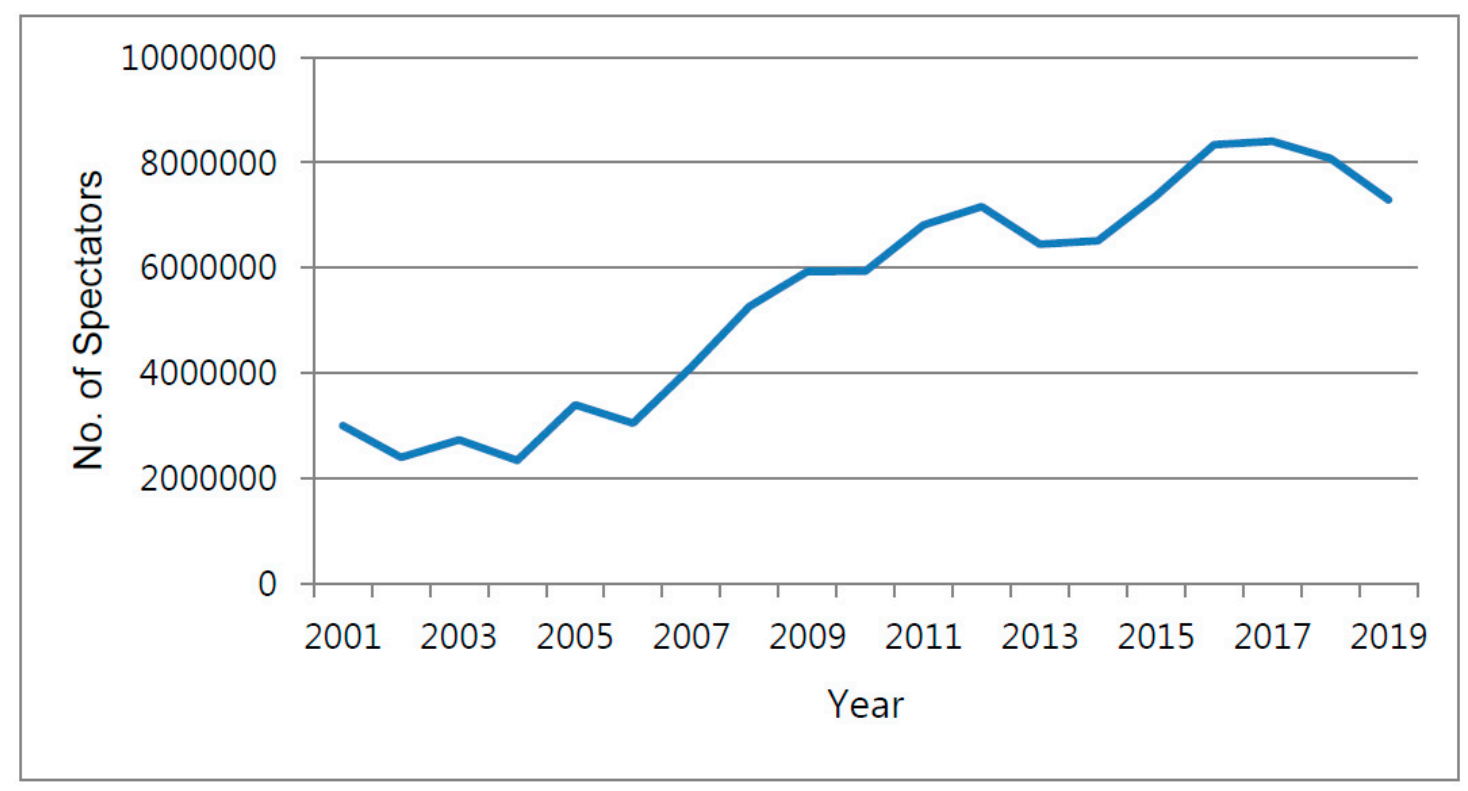

Figure 1. Regular season attendance, 2001-2019. 
The objective of this paper is to investigate the effect of competitive balance (CB) on the seat occupancy rate (SOR). It tests the feasibility of the CB thesis for Korean professional baseball teams. And it explores alternative specifications for live attendance, including the effect of the home team's absolute strength. More specifically, we examine the extent to which the winning percentage (WP) of the home team against all other teams and the WP of the home team against the visiting team affect SOR.

\section{Literature Review}

There has been extensive research on the factors that determine spectator attendance [25-28]. Noll (1974), who performed one of the earliest but most comprehensive studies on professional baseball attendance, introduced various independent variables for explaining season attendance [29]. These variables are grouped into three categories. The first category refers to a team's athletic quality (e.g., the team's league standing, closeness of the pennant race in the team's division, recent pennant win, and number of star players). The second includes demographic and socioeconomic variables (e.g., the population of the city where the home team resides, the proportion of black people, and the income per capita of the city). The third category indicates other factors that affect attracting spectators to stadiums (e.g., average ticket price, the age of the stadium, and sports competition vis-à-vis other professional sports teams in the city [1]). These explanatory variables have been widely replicated, revised, and expanded in later studies on sports attendance.

\subsection{Competitive Balance and Attendance}

Over the years, serious attention has been paid to competitive balance (CB) in sports leagues [30-33]. If leagues cannot maintain CB, fans will lose interest in games [34-37]. Therefore, CB constitutes a core of success in a professional sports league. Games of the league where inter-team CB is maintained, tend to keep attracting fans' interest. Thus, $\mathrm{CB}$ appeared to be a significant predictor of spectator attendance in league-wide games [19,31]. CB reflects the uncertainty of outcomes [38-40]. Uncertainty refers to the unpredictability of outcomes because of the similar athletic performance of two teams. $\mathrm{CB}$ indicates the degree of standardization of performance of teams in the league as viewed from the winning percentage (WP).

Earlier theoretical research on CB in professional sports was conducted by Rottenberg (1956) and El-Hodiri and Quirk (1971) [41,42]. According to the uncertainty-of-hypothesis (UOH) by Rottenberg (1956), consumers of sports games prefer a higher uncertainty of outcomes, and the predictability of outcomes in professional sports lowers the value of games as goods [42]. Likewise, El-Hodiri and Quirk (1971) argued that if we can predict the outcomes of matches, the number of spectators will be reduced [40]. Prior research reports that as in-game uncertainty becomes more significant (i.e., as the discrepancy in WP and/or ranking between competing teams becomes smaller), the attendance demand will be enhanced [28,43-45].

However, over the years, the UOH stating that spectators prefer games with uncertain outcomes has been debated under various conditions $[34,46]$. The UOH has been challenged by alternative specifications such as the effects of the home team's strength $[46,47]$ and absolute team strength $[48,49]$ on live attendance. Shakina et al. (2020) tested the UOH against the brand-team effect and found that fans prefer to watch good team play (including star players or brand teams) rather than highly competitive matches [49].

\subsection{Measurement Issues}

Since the 1970s, researchers have attempted to develop indicators for CB. Among others, such indices as standard deviation (SD) of winning percentages, relative standard deviation (RSD), and the Herfindal-Hischman Index (HHI) have been proposed and are widely used. The simplest way is to present the SD of each team's WP, that shows its distance from the mean value, supposedly to be a WP of 0.5 . Thus, the larger the SD is, the higher the competitive imbalance will be [50,51]. RSD is an 
SD of WP divided by an "ideal" SD. RSD overcomes the problem of comparability because the SD of WP varies depending on the number of games played by each team. The ideal SD is computed by dividing 0.5 by the total number of games. If the RSD becomes closer to one, CB is reached [51-53]. Recently, Lee, Kim, and Kim (2019) presented a biased-corrected standard deviation (BCSD) as a new estimator of SD on the ground that RSD and actual SD are biased, and applied BCSD to the English Premier League and the Korea Baseball Organization [54].

The HHI was originally developed to figure out market concentration in the industry. The HHI is derived from the percentage of each team's winning games among the total winning games of all teams in the league. A HHI closer to zero indicates that the CB is reached [55-57]. SD, RSD, and the HHI all measure $\mathrm{CB}$ in a particular year. These indicators only reflect the total WP of each team in the season, never counting team standings. To overcome the limitations of these indicators, Mizak, Neral, and Stair (2007) proposed an alternative measure of $\mathrm{CB}\left(\mathrm{C}_{\mathrm{t}}\right.$; “Churn") incorporating changes in team standings over time [58]. The maximum value of the churn depends on league size. An adjusted churn equal to zero indicates no change in the standings from one year to the next, referring to minimal competitive balance in the league. On the other hand, the churn value being one indicates the maximum possible change in the standings over time, implying a high level of CB.

Despite various indices of $\mathrm{CB}$ developed over the years, WP of the home team appears to be the most pertinent indicator for attracting more spectators, as shown in earlier studies. Ordinary CB indices reflect $\mathrm{CB}$ in the league for the whole season, not $\mathrm{CB}$ between teams in a single game during the season. There has been an argument for introducing an index indicating competitiveness or $\mathrm{CB}$ between competing teams playing in each game during the season. To overcome the limitations of the existing indices that reflect only one figure for each year, we will use the WP records of the home and visiting teams and those of the home team and all teams (total WP) per game for the CB index. The uncertainty-of-outcome thesis states that when the WP is around a specific number (for example, 0.5), spectators are most likely to gather. As the WP becomes remote from this figure, the interest of spectators will diminish.

In this study, the total WP of the home team played before each game, and the record WP between home and visiting teams were included as independent variables. Specifically, based on individual games in each season, we observed whether the total WP of the home team and the record WP between home and visiting teams influence the fan attendance of each game. The WP of each season's first match was measured by the previous season's final record.

\subsection{Competitive Balance and SOR}

In earlier studies, the total number of spectators who attended a single game was often used as a measure of attendance because early leagues were less established, and small-scale stadiums were abundant [25]. However, many others used the attendance rate instead of raw total attendance. For example, Kaempfer and Pacey $(1986,180)$ used the average attendance ratio, which refers to the 'ratio of attendance in a given year to stadium size' [59]. Schollarert and Smith (1987) explored four different modes of measuring attendance: total season attendance, average percentage of seats sold, number of unsold seats per season, and per capita attendance (i.e., the average number of games attended by a resident of the metropolitan area, cf. Demmert 1973) $[43,60]$. This study will introduce SOR as an indicator of attendance. Welki and Zlaptoper (1999) measured game attendance by the proportion of the individual game tickets sold (game attendance plus no-shows) [61]. Therefore, we propose the following hypotheses:

Hypothesis 1a. The SOR of each baseball game will be determined by the total WP of the home team in the season played before the game.

Hypothesis $\mathbf{1 b}$. The SOR of each baseball game will be determined by the WP of the home team against the visiting team in the season played before the game. 
Hypothesis 2a. The SOR will increase as the athletic performance of the home team against all other teams in the league becomes closer to $C B$.

Hypothesis $\mathbf{2 b}$. The SOR will increase as the athletic performance of the home against the visiting team becomes closer to $C B$.

Fans are most likely concerned about their home team winning. Then, what factors attract home team fans to stadiums? There are two possibilities for athletic performance. One is the WP that the home team has achieved up to a certain point in the whole league, and the other is the WP that the home team has achieved in games with the visiting team. At this point, we may have to think about the relationship between WP and the fans' concerns, whether it be linear or curvilinear (i.e., as WP increases, the concerns also increase), or nonlinear (i.e., the concerns increase as WP increases, but up to a certain point, and beyond that point, concerns fall). The uncertainty-of-outcome thesis has dealt with curvilinearity issues [62,63]. Rascher and Solmes (2007) indicated that fans in professional sports wish and expect the home team to win, but do not want contests where the results are anticipated with certainty [64]. They reported that attendance would be maximized when the ex-ante probability of the home team winning is twice $(66 \%)$ the chance of the visiting team to win the game, implying an inverted U-shaped curvilinear relationship. Conversely, Shakina et al. (2020) reported the U-shape effect of the uncertainty of sport outcomes on attendance [49]. Greater attendance is expected at low and high levels of uncertainty than at the middle level of uncertainty. Therefore, we present the following hypotheses:

Hypothesis 3a. The relationship between $C B_{-} T$ (in the whole season) and SOR will be curvilinear such that the middle level of $C B$ will attract more spectators than low and high levels of $C B$.

Hypothesis $\mathbf{3 b}$. The relationship between $C B_{-} V$ (Competitive balance against visiting teams) (the home team against the visiting team) and SOR will be curvilinear such that the middle level of $C B$ will attract more spectators than low and high levels of $C B$.

\subsection{Other Factors Affecting SOR}

\subsubsection{Demographic and Socioeconomic Factors of Teams' Hometowns}

Prior research reported that the growth of the population of a city increases the number of spectators in stadiums $[31,65]$. In the case of the Korean baseball league, three of the total 10 teams are based in Seoul (see Appendix A). As the population increases, potential spectators may increase as well. Still, the capacity of a stadium accepts a limited number of people, and thus, population growth does not turn into the growth of spectators. In particular, the number of people living in the Seoul Metropolitan Area exceeds 20 million, and seats in stadiums turn out to be a factor to discourage the growth of spectators. If the capacity of a stadium in the town increases faster than the growth of the local population, the SOR might shrink. Prior research also reported that income per capita enhances the intention to watch sports games, and therefore has a positive impact on the number of spectators $[12,61,66]$. Thus, it is presumed that the SOR will be raised by population size in the hometowns of the home and visiting teams. The SOR will also be raised by income level in the hometowns of the home and visiting teams.

\subsubsection{Television Audience}

There has been research on differences in fans' preference for CB between stadium attendees and television viewers [67]. Buraimo and Simmons (2009) found that stadium fans prefer matches with outcome certainty, while TV viewers prefer unpredictable to more predictable contests [67]. There is also a study on the comparison between the market for live game attendance and the market for television [68]. Buraimo (2008) argues that there is a reciprocal relationship between stadium 
attendance and the size of television audiences [69]. However, previous studies provide inconsistent evidence on how live TV broadcasts affect match attendance. There have been opposing arguments. One argues that televised matches reduce gate attendance [26,70], while the other reports that the effect of live telecasts on gate attendance is negligible [19,71]. Borland and MacDonald (2003) highlighted the point that although the live TV broadcast of a match may lower stadium attendance for that match, the telecast may also boost interest in sports competitions and eventually enhance total presence [19]. Thus, the SOR will be affected by the TV viewer ratings of games by the home and visiting teams.

\subsubsection{Scheduling}

Scheduling of games also affects gate attendance. In general, fans of professional sports prefer games played on weekends when they can enjoy free leisure time rather than those on weekdays. Paul and Weinbach (2011) argued that the highest attendance for games is shown on weekends when the opportunity cost of fans' time is lower [72]. However, the impact of the scheduling of matches on attendance is very complicated. Forrest and Simmons (2006) reported that televised Champions League games played on weekdays have profoundly negative impacts on lower division League gate attendance [73]. Thus, the SOR will be higher on weekends than on weekdays.

\section{Methods}

\subsection{Data}

Data were collected from the archives of the Korea Baseball Organization (KBO), Statistics Korea, and Nielsen TV ratings published by Nielsen Korea. Game records and SOR were drawn from the website of the KBO (2018), including information on all baseball games of 10 Korean professional baseball teams in the league during the 2015-2017 seasons [74]. There were 2160 games altogether during the three years, with each season consisting of 720 games. From 2015, each team played 144 games.

\subsection{Measures}

\subsubsection{Seat Occupancy Rate (SOR)}

SOR is calculated by dividing the number of seated spectators by the maximum number of people who can sit in a stadium. Data on SOR were drawn from the website of the KBO (2019) [75]. The KBO reports such information each year.

\subsubsection{Winning Percentage (WP)}

WP is calculated by dividing the number of games a team has won by the total number of games the team has played. The WP of each team per game during the period of 2015-2017 was calculated based on the homepage of the KBO and the Yearbook of Professional Baseball.

\subsubsection{Competitive Balance (CB)}

Competitive balance against visiting teams $\left(\mathrm{CB}_{-} \mathrm{V}\right)$ is measured by the difference between the home team's WP against the visiting teams (HWP) and ties (50\% of WP). Likewise, CB_T indicates the difference between the home team's WP against all other teams in the league (HWP_T) and ties ( $50 \%$ of WP), as shown below. We take the absolute value regardless of its sign, and thus, they are all non-negative numbers. HWP and HWP_T are calculated for each game using the WP data available up to the game day. Thus, the smaller figures indicate that $\mathrm{CB}$ is more closely reached.

$$
\begin{gathered}
C B \_V=|H W P-0.5| \\
C B \_T=\left|H W P \_T-0.5\right|
\end{gathered}
$$




\subsubsection{Control Variables}

Sociodemographic variables: The population of the hometown of each team is drawn from data of the resident registration survey carried out by the Ministry of the Interior and Safety in April of each year when the professional baseball league season starts. Population was measured in 10,000 persons. Data on the average income of each team's hometown are drawn from the Statistics Survey carried out each year by Statistics Korea. Income was measured by real income per capita in 10,000 won (equivalent to US\$ 8.3). Since three teams have Seoul as their hometown, population and income are the same for the three teams.

$T V$ viewer ratings: TV viewer ratings for games of the home and visiting teams are drawn from Nielsen rating data on the average annual viewer ratings of each professional baseball team.

Weekend dummy: The number of spectators differs between weekdays and weekends. The days of the weekend (Friday, Saturday, Sunday, and Holidays) were coded as 1 and the rest (Tuesday, Wednesday, and Thursday) as 0 . There are no games on Mondays.

\subsection{Empirical Analysis}

This study attempted to investigate the effect of the CB index on the attraction of spectators in professional baseball games. Data were analyzed using the program SPSS version 25 . First, by using the data of three-year records from 2015 through 2017, we analyzed whether the level of CB of the home team influences the spectator mobilization in each game. Although a high level of CB is attained at the overall league level, as far as fans are concerned, the games of the team they support may be more important to them regardless of $C B$ than the games of the two teams they do not support playing at a similar level. Additionally, since the $\mathrm{CB}$ index shown above measures the level of $\mathrm{CB}$ of the whole league for a specific year, it is necessary to observe inter-team $C B$ and the number of spectators in each game of a specific season in order to analyze the capability of attracting spectators in each game and the level of CB between two teams in a more specific and elaborated way. Thus, this study examines major determinants of $\mathrm{CB}$ using all games of each season during the three years since 2015, when the professional baseball league was established with 10 teams. Furthermore, the income level and population size of the home and visiting teams' hometowns and TV viewer ratings were also introduced as control variables. To test the curvilinear effect of CB on SOR, we also inserted CB_V squared (CBSQ_V) and CB_T squared (CBSQ_T). For this analysis, a regression equation was used. To test the hypotheses, three models will be analyzed.

\section{Results}

Table 1 presents the means, standard deviations, and minimum and maximum of the study variables.

The results of data analysis are reported in Table 2. Hypotheses $1 \mathrm{a}$ and $1 \mathrm{~b}$ proposed that the overall athletic performance of the home team against all other teams in the league and the visiting team, respectively, will enhance the SOR. In Model 1 of Table 2, controls and winning percentages were entered as independent variables. Control variables include the income of the home and visiting team's provinces, population of the home and visiting team's hometowns, TV viewer ratings of the home and visiting team's games, and weekend dummy. Winning percentages refer to home team winning percentages against visiting teams and for whole seasons. The winning percentage (WP) of the home team in the season played before the match (HWP_T) was found to be statistically significant $(\beta=0.23, p<0.001)$, but the WP of the home team against the visiting team (HWP) was not $(\beta=0.01$, $p=0.420$, n.s.). Thus, only Hypothesis 1a was supported. 
Table 1. Descriptive statistics of study variables $(\mathrm{N}=2160)$.

\begin{tabular}{lcc}
\hline \multicolumn{1}{c}{ Variables } & Mean & SD \\
\hline Seat occupancy rate (SOR) & 0.57 & 0.24 \\
Home team winning \% against visiting team (HWP) & 0.51 & 0.24 \\
Home team winning \% for whole seasons (HWP_T) & 0.50 & 0.12 \\
Competitive balance with a visiting team (CB_V) & 0.18 & 0.16 \\
Competitive balance with entire teams (CB_T) & 0.08 & 0.09 \\
Income of home team's province (INCH) & 18,107 & 1698 \\
Income of visiting team's province (INCA) & 18,101 & 1671 \\
Population of home team's hometown (POPH) & 432 & 368 \\
Population of visiting team's hometown (POPA) & 437 & 365 \\
TV viewer ratings of home team games (TVH) & 1.00 & 0.31 \\
TV viewer ratings of visiting team games (TVA) & 1.00 & 0.31 \\
Weekends dummy (WEDUM) & 0.52 & 0.50 \\
\hline
\end{tabular}

Table 2. Results of regression analyses for seat occupancy rate (SOR).

\begin{tabular}{|c|c|c|c|}
\hline Independent Variables & Model 1 & Model 2 & Model 3 \\
\hline \multicolumn{4}{|l|}{ Controls } \\
\hline Income of home team's province (INCH) & $0.39 * * *$ & $0.26^{* * *}$ & $0.38^{* * *}$ \\
\hline Income of visiting team's province (INCA) & $0.35^{* * *}$ & $0.42 * * *$ & $0.35^{* * *}$ \\
\hline Population of home team's hometown (POPH) & $-0.31^{* * *}$ & $-0.12 *$ & $-0.29^{* * *}$ \\
\hline Population of visiting team's hometown (POPA) & $-0.28^{* * *}$ & $-0.36^{* * *}$ & $-0.28^{* * *}$ \\
\hline TV viewer ratings of home team games (TVH) & $0.17^{* * *}$ & $0.20^{* * *}$ & $0.17^{* * *}$ \\
\hline TV viewer ratings of visiting team games (TVA) & $0.34^{* * *}$ & $0.34^{* * *}$ & $0.35^{* * *}$ \\
\hline Weekends dummy (WEDUM) & $0.43^{* * *}$ & $0.43^{* * *}$ & $0.43^{* * *}$ \\
\hline \multicolumn{4}{|l|}{ Winning percentage } \\
\hline Home team winning \% against visiting team (HWP) & 0.01 & & 0.01 \\
\hline Home team winning \% for whole seasons $\left(\mathrm{HWP}_{-} \mathrm{T}\right)$ & $0.23^{* * *}$ & & $0.23^{* * *}$ \\
\hline \multicolumn{4}{|l|}{ Competitive balance } \\
\hline Competitive balance with a visiting team (CB_V) & & -0.01 & 0.00 \\
\hline Competitive balance with entire teams (CB_T) & & $0.17^{* * *}$ & $0.08^{+}$ \\
\hline CB_V squared (CBSQ_V) & & 0.05 & 0.04 \\
\hline CB_T squared (CBSQ_T) & & $-0.22 * * *$ & $-0.10 *$ \\
\hline$R^{2}$ & 0.36 & 0.32 & 0.36 \\
\hline
\end{tabular}

In Model 2, we tested Hypotheses $2 \mathrm{a}$ and $2 \mathrm{~b}$ concerning the effect of competitive balance with all other teams in the league $\left(\mathrm{CB}_{-} \mathrm{T}\right)$ and the visiting team in particular $\left(\mathrm{CB}_{-} \mathrm{V}\right)$ on gate attendance. CB_T was found to be significant $(\beta=0.17, p<0.001)$, but $C_{-}$_V was not $(\beta=-0.01, p=0.865$, n.s.). The results support Hypothesis $2 \mathrm{a}$, but not Hypothesis $2 \mathrm{~b}$. To test a curvilinear relationship between competitive balance and SOR, we also introduced CB_V squared (CBSQ_V) and CB_T squared (CBSQ_T). CBSQ_T was found statistically significant at the $0.1 \%$ level $(\beta=-0.22, p<0.001)$, indicating an inverted U-shaped relationship. This supports Hypothesis $3 a$ but does not support Hypothesis $3 \mathrm{~b}$ concerning CBSQ_V $(\beta=0.05, p=0.431$, n.s. $)$.

The relationship between competitive balance and SOR is illustrated in Figure 2. As CB decreases (i.e., the larger figures indicate a higher level of competitive imbalance), SOR will be raised, but to a certain point, and then lowered. It implies that the highest SOR might be reached at some mid-point of $\mathrm{CB}$, neither at the lowest nor highest level of $\mathrm{CB}$. 


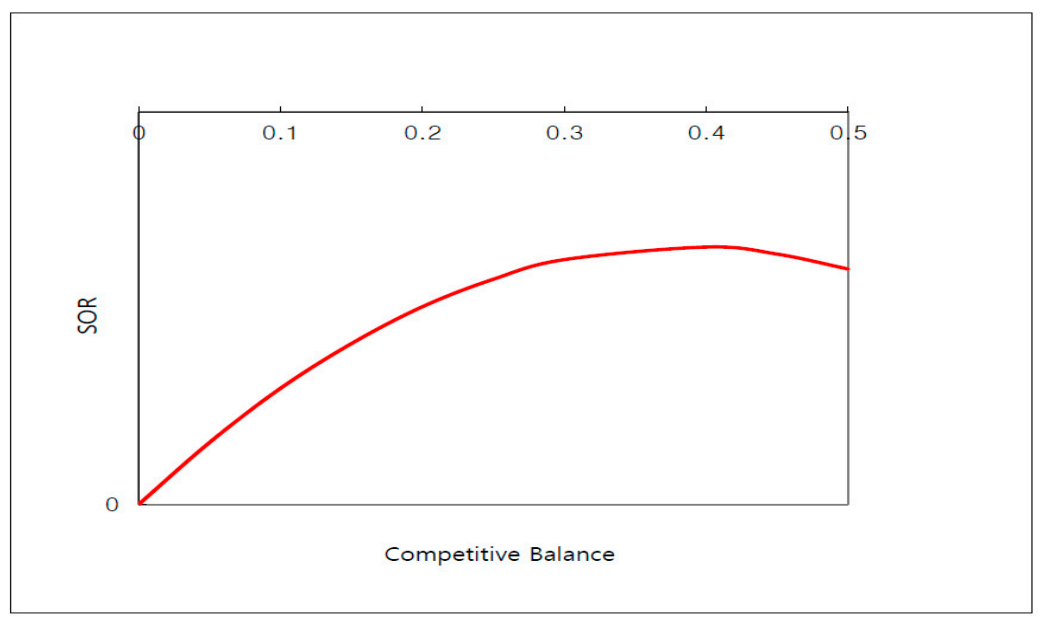

Figure 2. Inverted U-shaped curvilinear relationship between competitive balance and seat occupancy rate.

In the full model in Model 3, the WP of the home team against all other teams in the season played before the match (HWP_T) consistently turned out to be significant $(\beta=0.23, p<0.001)$. The results also show that CBSQ_T is statistically significant $(\beta=-0.10, p<0.05)$ and CB_T is significant at the $10 \%$ level $(\beta=0.08, p=0.061)$. This implies that the overall athletic performance of the home team in the league competing with all other teams is more important than the home team's competitive balance in the season played before the game for attracting fans to the stadium.

\section{Discussion}

Our findings clearly show that although spectator attendance depends on the extent of the home team's CB against all other teams, it is more critical for the home team to show prominent WP records. Lemke et al. (2010) also presented that the home team's winning probability will steadily increase attendance, in contrast to the $\mathrm{UOH}$ [76]. This result is incompatible with other earlier research reporting that as the difference in ranking between the home and visiting teams becomes smaller, the heightened uncertainty of outcomes will have a positive effect on attendance demand [28,43-45]. Overall, the effect of CB between the home and visiting teams on the SOR appears to be less than that of the total WP of the home team in the league. Thus, the results of this study imply that fans make more visits when the home team performs with a high WP in matches with other teams in the league than when $\mathrm{CB}$ between the home and visiting teams is maintained and thus their matches are expected to be highly competitive.

As viewed from games in the Korean professional baseball league, contests between high-ranking teams always attract spectator attendance. For example, in matches between the Doosan Bears and LG Twins in Seoul, a significant number of spectators gathered regardless of their CB. The reason for the relative non-importance of $\mathrm{CB}$ between the home and visiting teams is due to fandom. In the away games of teams such as the Kia Tigers cheered on by enthusiastic fandom groups, fans are mobilized, whereas newly inaugurated teams such as the KT Wiz attract a relatively smaller number of fans in away games. The size of the fan base of the home and visiting teams may offset the effect of $\mathrm{CB}$ on spectator attendance.

As to control variables that might affect the SOR, the population of the teams' hometown has a negative impact on the SOR in all models. This result is contrary to earlier studies reporting that the growth of the city population significantly affects the number of spectators [31,65]. Teams with a large city as the hometown are more likely to attract spectators than those in a smaller town. However, the number of spectators per population and the SOR may be lower. For example, the population growth rate of the hometown could be associated with the growth rate of seats in stadiums.

Moreover, in such metropolitan cities as Seoul and Busan where a large proportion of people move in from other cities and towns, the percentage of fans who identify themselves as long-time residents 
of the hometown could be smaller. In this case, the growth of the population may not raise or even lower the SOR. In these metropolitan cities, migrants from other regions may be supportive of the team from their hometown rather than the team of the town where they are residing at present. The larger the population size, the smaller the proportion of fans for the home team, and therefore, the SOR will be lower. As viewed from a slightly different perspective, it may be a plausible interpretation that people living in larger cities are more likely to enjoy a variety of leisure activities than those in smaller towns. Thus, the former will show a lower level of loyalty to the home team than the latter.

In all models in Table 2, it was shown that the TV ratings of home and visiting team games raised the SOR of the home team's stadium. It was consistently shown that more people gather in stadiums on weekends and holidays than on weekdays. Televised games on weekdays also negatively affect gate attendance [73]. This result is consistent with earlier research [72]. To promote spectators on workdays, the baseball clubs exert various efforts, including charging different entrance fees on weekdays and weekends.

Finally, it is worth noting that there exists an inverted U-shaped curvilinear relationship between $\mathrm{CB}$ and SOR. Fans are more likely to gather in stadiums when the $\mathrm{CB}$ of the home team against the visiting team is in the middle than when it is either at a high or low level of $\mathrm{CB}$. This result is consonant with Rascher and Solmes' (2007) argument that the maximum level of live attendance would be achieved when the predicted probability of the home team winning is twice the chance of the visiting team to win the game. Such a curvilinear relationship needs more scrutiny in future studies [64].

\subsection{Implications for Practice}

This study indicated that the WP of the home team played a more critical role than the CB of the home team against an away team for raising the SOR of the home team in Korean professional baseball games. The SOR of the home team in each set is also contingent upon the extent to which the visiting team has nationwide fandom.

This study has practical implications as follows. First, at the individual club level, it is suggested to reinforce its competitiveness to raise the WP of the team and to keep fans attracted to home team games throughout the season by creating competitive matches via the introduction of storytelling techniques. At the league level, it is suggested to develop a variety of projects and policies for maintaining an appropriate $\mathrm{CB}$ between its member teams and enhancing the athletic performance of all the teams in the league through sustainable management. Noticeably, the athletic performance of players in the Korean baseball league has declined since 2015 when the league expanded to 10 teams because the layer of players became thinner. Accordingly, the number of spectators has also decreased since 2017. Therefore, it is also recommended to improve the system for recruiting good players, including increasing the number of foreign players on each team.

Second, to settle professional baseball in Korea, it is necessary to beat other professional sports. Baseball games take longer than other major sports games, and thus it may not be appealing to younger generations who are more in favor of speedy events and expect fast results. Athletic performance no longer plays a vital role compared to the past, and so alternative strategies for securing fans need to be found. In recent years, the Korean league explored various types of sportainment as already implemented in US professional baseball and started to introduce virtual reality and augmented reality in stadiums to attract diverse age groups. These ideas need to be further developed and expanded in the future.

Third, this study showed that TV viewers of home team and visiting team affect the SOR in a significant way, which means that the number of loyal fans may contribute significantly to an increase in the SOR. Unlike the US sports market, where people can watch almost all games by paying, except for live games broadcast nationwide, all the games of the Korean professional baseball league can be watched on cable TV for free. The sets of the baseball league have longer seasons, with more matches attracting more spectators than other professional sports. For this reason, athletic performance 
appealing to fans through TV, storytelling specific to professional baseball, and star marketing may help promote gate attendance and SOR.

Fourth, after a delay of more than one month due to the coronavirus (Covid-19) pandemic, the Korea professional baseball league opened its regular season without spectators on 5 May 2020. Viewers of televised games reached more than 2 million people for the games held simultaneously in five major cities [77]. A match between the Doosan Bears and LG Twins, the two competing champions, was played without spectators and recorded the highest viewer rate. Covid-19 reminds us of the meaning and value of the physical attendance of fans in stadiums. The Korean league has turned its games into "no spectator" ones for the time being as a measure to fight against the coronavirus pandemic. However, the outbreak of Covid19 entered a new historical era of professional sports without spectators and raised the question of how to cope with such a great challenge. The social and financial effects on the business of professional baseball need to be re-evaluated later on after all these risky seasons are over.

\subsection{Limitations and Suggestions for Future Research}

The findings of the present study have to be interpreted subject to some limitations. This study covered the period of 2015-2017, but the years after this period saw a little bit of a downturn in terms of spectators, as shown in Figure 1. Additionally, in 2020, the season itself shows a quite different pattern from the earlier ones because of the Covid-19 pandemic. Its effects are still ongoing since games have been played in 2020 both with and without spectators, and with only a small percentage (10 30\%) of seats open to the fans. Once these hard times are over, we may have to reconsider all the issues raised in this paper and look at the games from a totally different perspective. We presume that the pros and cons of online sports without spectators may not be an anomaly but become a significant part of professional sports. We have to leave these issues for future research.

\section{Conclusions}

The uncertainty-of-outcome thesis should be re-evaluated. Although prior research on CB has confirmed its empirical validity, a more rigorous and diverse analysis is needed to accept its validity. Neutral spectators or TV viewers may be more interested in competitive matches, but fans who support a specific team will be more in favor of their team winning games. The results of this study show that as the WP of the team supported increases, a higher SOR of the stadium will be attained.

Over the years, the number of professional baseball spectators has increased, but the rate of growth turns out to not be that high. The size of the population and income level influenced the increase in the SOR. Notably, the rise in income leads to an increase in spectators. Concerning fandom, the average annual TV viewer ratings of the games between home and visiting teams should be considered. Great enthusiasm by fandom groups positively increased the SOR. In the long run, the rapid decrease in the fertility rate that Korean society currently suffers from may reduce prospective young players and lessen the players' athletic performance. Accordingly, the number of spectators naturally decreases and eventually constricts the professional sports market further. Therefore, if media has positive effects on fandom formation, the league and clubs have to devote their efforts to strengthening the PR strategy to attract fans and arouse the interest and concern of the young generation [78].

Author Contributions: S.H.S. and S.Y.S. designed the research model. S.H.S. developed the theory, carried out collecting data, and implemented a major part of data analysis. D.-S.H. contributed to the final version of the manuscript by providing critical feedback. All authors have read and agreed to the published version of the manuscript.

Funding: This research received no external funding.

Conflicts of Interest: The authors declare no conflict of interest. 


\section{Appendix A}

Table A1. Population Size and Base Stadium Capacity of the Hometown of Korean Professional Baseball Teams.

\begin{tabular}{llcc}
\hline \multicolumn{1}{c}{ Team } & \multicolumn{1}{c}{ Home Stadium } & $\begin{array}{c}\text { Population of } \\
\text { Hometown (in 1000) }\end{array}$ & $\begin{array}{c}\text { Stadium Capacity } \\
\text { (in Person) }\end{array}$ \\
\hline Doosan Bears & Seoul Jamsil Stadium & 9805 & 25,000 \\
\hline LG Twins & Seoul Jamsil Stadium & 9805 & 25,000 \\
\hline Nexen Heroes & Seoul Gocheok Dome & 9805 & 17,000 \\
\hline KT Wiz & Suwon KT Wiz Park & 1231 & 22,000 \\
\hline SK Wyverns & Incheon SK Happy Dream Park & 2913 & 26,000 \\
\hline Hanwha Eagles & Daejeon Hanwha Life Eagles Park & 1535 & 13,000 \\
\hline Samsung Lions & Daegu Samsung Lions Park & 2461 & 24,000 \\
\hline Lotte Giants & Busan Sajik Stadium & 3440 & 26,800 \\
\hline NC Dinos & Masan Baseball Stadium & 1069 & 11,000 \\
\hline Kia Tigers & Gwangju-Kia Champions Field & 1501 & 20,500 \\
\hline
\end{tabular}

\section{References}

1. Baade, R.A.; Tiehen, L.J. An analysis of major league baseball attendance, 1969-1987. J. Sport Soc. Issues 1990, 14, 14-32. [CrossRef]

2. Lawson, H.A. Empowering people, facilitating community development, and contributing to sustainable development: The social work of sport, exercise, and physical education programs. Sport Educ. Soc. 2005, 10, 135-160. [CrossRef]

3. Schulenkorf, N. Sustainable community development through sport and events: A conceptual framework for sport-for-development projects. Sport Manag. Rev. 2012, 15, 1-12. [CrossRef]

4. Lindsey, I.; Darby, P. Sport and the sustainable development goals: Where is the policy coherence? Int. Rev. Sociol. Sport 2018, 54, 793-812. [CrossRef]

5. Cho, W. A study of the economic validation of public goods generated by a professional sport stadium. Korean J. Sport Manag. 2015, 20, 1-17.

6. Van Reeth, D. The finances of professional cycling teams. In The Economics of Professional Road Cycling; Larsen, D.J., Van Reeth, D., Eds.; Springer: Cham, Switzerland, 2016; Volume 11, pp. 55-82.

7. JoongAng Daily. Pro Baseball beyond 500 Billion Won of Sales: 10 Million Spectators Coming Soon. 2018. Available online: http://news.joins.com/article/22823755 (accessed on 12 July 2019).

8. Ministry of Culture, Sports and Tourism (MCST). Sports Industry White Paper, 2017. Sejong-si, Korea. 2018. Available online: http://index.go.kr/potal/main/EachDtPageDetail.do?idx_cd=1662 (accessed on 5 January 2020).

9. Hill, B.; Green, B.C. Repeat attendance as a function of involvement, loyalty, and the sportscape across three football contexts. Sport Manag. Rev. 2000, 3, 145-162. [CrossRef]

10. Jang, H.; Lee, Y.H. A business analysis of Asian baseball leagues. Asian Econ. Policy Rev. 2016, 11, $95-112$. [CrossRef]

11. Seol, S.; Kim, Y. Sports Economics; Orae: Seoul, Korea, 2011. (In Korean)

12. Coates, D.; Harrison, T. Baseball strikes and the demand for attendance. J. Sports Econ. 2005, 6, $282-302$. [CrossRef]

13. Jewell, R.T. The effect of marquee players on sports demand: The case of U.S. major league soccer. J. Sports Econ. 2017, 18, 239-252. [CrossRef]

14. Maxcy, J.; Mondello, M. The impact of free agency on competitive balance in North American professional team sports leagues. J. Sport Manag. 2006, 20, 345-365. [CrossRef]

15. Binder, J.J.; Findlay, M. The Effects of the Bosman ruling on national and club teams in Europe. J. Sports Econ. 2012, 13, 107-129. [CrossRef] 
16. Breitbarth, T.; Walzel, S.; Van Eekeren, F. 'European-ness' in social responsibility and sport management research: Anchors and avenues. Eur. Sport Manag. Q. 2019, 19, 1-14. [CrossRef]

17. Drewes, M. Competition and efficiency in professional sports leagues. Eur. Sport Manag. Q. 2003, 3, $240-252$. [CrossRef]

18. Scelles, N.; Helleu, B.; Durand, C.; Bonnal, L. Professional sports firm values. J. Sports Econ. 2016, 17, 688-715. [CrossRef]

19. Borland, J.; Macdonald, R. Demand for sport. Oxf. Rev. Econ. Policy 2003, 19, 478-502. [CrossRef]

20. Ellmer, E.M.M.; Rynne, S.B. Professionalisation of action sports in Australia. Sport Soc. 2018, 22, $1742-1757$. [CrossRef]

21. Watanabe, N.M. Japanese professional soccer attendance and the effects of regions, CB, and rival franchises. Int. J. Sport Financ. 2012, 7, 309-323.

22. Lee, J.W.; Tan, T.C. The rise of sport in the Asia-Pacific region and a social scientific journey through Asian-Pacific sport. Sport Soc. 2019, 22, 1319-1325. [CrossRef]

23. Fort, R.; Kang, J.H.; Lee, Y.H. KBO and international sports league comparisons. In The Sports Business in the Pacific Rim: Economics and Policy; Lee, Y.H., Fort, R., Eds.; Springer: New York, NY, USA, 2015; pp. 175-193.

24. Ministry of Culture, Sports and Tourism (MCST). AVERAGE Number of Spectators per Game by Major Professional Sports. 2020. Available online: http://index.go.kr/potal/main/EachDtPageDetail.do?idx_cd=1662 (accessed on 23 August 2020).

25. DeSchriver, T.D.; Jensen, P.E. Determinants of spectator attendance at NCAA Division II football contests. J. Sport Manag. 2002, 16, 311-330. [CrossRef]

26. García, J.; Rodríguez, P. The determinants of football match attendance revisited: Empirical evidence from the Spanish Football League. J. Sports Econ. 2002, 3, 18-38. [CrossRef]

27. Lim, N.; Pedersen, P.M. Examining determinants of sport event attendance: A multilevel analysis of a major league baseball season. J. Glob. Sport Manag. 2018. [CrossRef]

28. Meehan, J.W., Jr.; Nelson, R.A.; Richardson, T.V. Competitive balance and game attendance in Major League Baseball. J. Sports Econ. 2007, 8, 563-580. [CrossRef]

29. Noll, R.G. Attendance and Price Setting. In Government and the Sports Business; Nol, R.G., Ed.; Brookings Institution: Washington, DC, USA, 1974; pp. 115-157.

30. Dietl, H.M.; Grossmann, M.; Lang, M. Competitive balance and revenue sharing in sports leagues with utility-maximizing teams. J. Sports Econ. 2011, 12, 284-308. [CrossRef]

31. Levin, M.A. The value of competition: Competitive balance as a predictor of attendance in spectator sports. Int. J. Sports Mark. Spons. 2009, 11, 2-19. [CrossRef]

32. Owen, P.D.; King, N. Competitive balance measures in sports leagues: The effects of variation in season length. Econ. Inq. 2014, 53, 731-744. [CrossRef]

33. Zimbalist, A.S. Competitive balance in sports leagues. J. Sports Econ. 2002, 3, 111-121. [CrossRef]

34. Coates, D.; Humphreys, B.R. Week to week attendance and competitive balance in the National Football League. Int. J. Sport Financ. 2010, 5, 239-252.

35. Fort, R.; Maxcy, J. Comment: Competitive balance in sports leagues: An introduction. J. Sports Econ. 2003, 4, 154-160. [CrossRef]

36. Larsen, A.; Fenn, A.J.; Spenner, E.L. The impact of free agency and the salary cap on competitive balance in the National Football League. J. Sports Econ. 2006, 7, 374-390. [CrossRef]

37. Quirk, J.; Fort, R. Pay Dirt: The Business of Professional Team Sports; Princeton University Press: Princeton, NJ, USA, 1992.

38. Fort, R.; Lee, Y.H. Structural change, competitive balance, and the rest of the major leagues. Econ. Inq. 2007, 45, 519-532. [CrossRef]

39. Humphreys, B.R. Alternative measures of competitive balance in sports leagues. J. Sports Econ. 2002, 3, 133-148. [CrossRef]

40. Taylor, P.; Gratton, C. The Economics of Sports and Recreation: An Economic Analysis; Routledge: New York, NY, USA, 2002.

41. El-Hodiri, M.; Quirk, J. An economic model of a professional sports league. J. Political Econ. 1971, 79, 1302-1319. [CrossRef]

42. Rottenberg, S. The baseball players' labor market. J. Political Econ. 1956, 64, 242-258. [CrossRef]

43. Demmert, H.G. The Economics of Professional Team Sports; Lexington Books: Lexington, MA, USA, 1973. 
44. Hill, J.R.; Madura, J.; Zuber, R.A. The short run demand for major league baseball. Atl. Econ. J. 1982, 10, 31-35. [CrossRef]

45. Fort, R.; Rosenman, R. Streak management. In Sports Economics: Current Research; Fizel, E.G.J., Hadley, L., Eds.; Praeger Publishers: Westport, CT, USA, 1999; pp. 119-134.

46. Paul, R.J.; Wachsman, Y.; Weinbach, A.P. The role of uncertainty of outcome and scoring in the determination of fan satisfaction in the NFL. J. Sports Econ. 2010, 12, 213-221. [CrossRef]

47. Hogan, V.; Massey, P.; Massey, S. Analysing match attendance in the European Rugby Cup: Does uncertainty of outcome matter in a multinational tournament? Eur. Sport Manag. Q. 2017, 17, 312-330. [CrossRef]

48. Sacheti, A.; Gregory-Smith, I.; Paton, D. Uncertainty of outcome or strengths of teams: An economic analysis of attendance demand for international cricket. Appl. Econ. 2014, 46, 2034-2046. [CrossRef]

49. Shakina, E.; Gasparetto, T.; Barajas, A. Football fans' emotions: Uncertainty against brand perception. Front. Psychol. 2020, 11, 659. [CrossRef]

50. Leeds, M.A.; von Allmen, P.; Matheson, V.A. The Economics of Sports, 6th ed.; Routledge: New York, NY, USA, 2010.

51. Scully, J.R. The Business of Major League Baseball; University of Chicago Press: Chicago, IL, USA, 1989.

52. Fort, R.; Quirk, J. Cross-subsidization, incentives, and outcomes in professional team sports leagues. J. Econ. Lit. 1995, 33, 1265-1299.

53. Noll, R.G. The economics of sports leagues. In Law of Professional and Amateur Sports; Clark Boardman: Deerfield, MA, USA, 1988.

54. Lee, Y.H.; Kim, Y.; Kim, S. A bias-corrected estimator of competitive balance in sports leagues. J. Sports Econ. 2018, 20, 479-508. [CrossRef]

55. Depken, C.A. Free-agency and the competitiveness of Major League Baseball. Rev. Ind. Organ. 1999, 14, 205-217. [CrossRef]

56. La Croix, S.J.; Kawaura, A. Rule changes and competitive balance in Japanese professional baseball. Econ. Inq. 1999, 37, 353-368. [CrossRef]

57. Owen, P.D.; Ryan, M.; Weatherston, C.R. Measuring competitive balance in professional team sports using the Herfindahl-Hirschman Index. Rev. Ind. Organ. 2007, 31, 289-302. [CrossRef]

58. Mizak, D.; Neral, J.; Stair, A. The adjusted churn: An index of competitive balance for sports leagues based on changes in team standings over time. Econ. Bull. 2007, 26, 1-7.

59. Kaempfer, W.H.; Pacey, P.L. Televising college football: The complementarity of attendance and viewing. Soc. Sci. Q. 1986, 67, 176-185.

60. Schollaert, P.T.; Smith, D.H. Team racial composition and sports attendance. Sociol. Q. 1987, 28, 71-87. [CrossRef]

61. Welki, A.M.; Zlatoper, T.J. US professional football: The demand for game-day attendance in 1991. Manag. Decis. Econ. 1994, 15, 489-495. [CrossRef]

62. Coates, D.; Humphreys, B.R.; Zhou, L. Reference-dependent preferences, loss aversion, and live game attendance. Econ. Inq. 2014, 52, 959-973. [CrossRef]

63. Serrano, R.; García-Bernal, J.; Fernández-Olmos, M.; Espitia-Escuer, M.A. Expected quality in European football attendance: Market value and uncertainty reconsidered. Appl. Econ. Lett. 2015, 22, 1051-1054. [CrossRef]

64. Rascher, D.A.; Solmes, J. Do fans want close contests? A test of the uncertainty of outcome hypothesis in the National Basketball Association. SSRN Electron. J. 2007, 2, 130-141. [CrossRef]

65. Robinson, M.J.; DeSchriver, T.D. Consumer differences across large and small market teams in the National Professional Soccer League. Sport Mark. Q. 2003, 12, 80-87.

66. McEvoy, C.D.; Nagel, M.; DeSchriver, T.D.; Brown, M.T. Facility age and attendance in Major League Baseball. Sport Manag. Rev. 2005, 8, 19-41. [CrossRef]

67. Buraimo, B.; Simmons, R. A tale of two audiences: Spectators, television viewers and outcome uncertainty in Spanish football. J. Econ. Bus. 2009, 61, 326-338. [CrossRef]

68. Mongeon, K.; Winfree, J.A. Comparison of television and gate demand in the National Basketball Association. Sport Manag. Rev. 2012, 15, 72-79. [CrossRef]

69. Buraimo, B. Stadium attendance and television audience demand in English league football. Manag. Decis. Econ. 2008, 29, 513-523. [CrossRef]

70. Baimbridge, M.; Cameron, S.; Dawson, P. Satellite television and the demand for football: A whole new ball game? Scott. J. Political Econ. 1996, 43, 317-333. [CrossRef] 
71. Forrest, D.; Simmons, R.; Szymanski, S. Broadcasting, attendance and the inefficiency of cartels. Rev. Ind. Organ. 2004, 24, 243-265. [CrossRef]

72. Paul, R.J.; Weinbach, A.P. Determinants of attendance in the Quebec Major Junior Hockey League: Role of winning, scoring, and fighting. Atl. Econ. J. 2011, 39, 303-311. [CrossRef]

73. Forrest, D.; Simmons, R. New issues in attendance demand. J. Sports Econ. 2006, 7, 247-266. [CrossRef]

74. Korea Baseball Organization (KBO). 2018. Available online: http://www.koreabaseball.com (accessed on 20 December 2018).

75. Korea Baseball Organization (KBO). History. 2019. Available online: http://www.koreabaseball.com/History/ Crowd/GraphYear.aspx (accessed on 5 January 2020).

76. Lemke, R.J.; Leonard, M.; Tlhokwane, K. Estimating attendance at major league baseball games for the 2007 season. J. Sports Econ. 2009, 11, 316-348. [CrossRef]

77. Maeil. The 2160 Thousand TV Watchers for the Opening Games of the Professional Baseball 'without Spectators'. 2020. Available online: http://www.m-i.kr/news/articleView.html?idxno=707559 (accessed on 8 May 2020).

78. Korea Institute of Sport Science. A Study of Development Plans by Four Major Sports; Unpublished Research Report; Korea Institute of Sport Science: Seoul, Korea, 2015. (In Korean)

(C) 2020 by the authors. Licensee MDPI, Basel, Switzerland. This article is an open access article distributed under the terms and conditions of the Creative Commons Attribution (CC BY) license (http://creativecommons.org/licenses/by/4.0/). 